\title{
Therapeutic Use Study
}

National Cancer Institute

\section{Source}

National Cancer Institute. Therapeutic Use Study. NCI Thesaurus. Code C39539.

The Therapeutic Use Study is a clinical study that is conducted with the purpose to refine understanding of therapy risk-benefit relationship in general or special populations and/or environments; to identify less common adverse reactions, and to refine dosing/regimen/indications recommendations. 